\title{
ПРОБЛЕМЫ РЕАЛИЗАЦИИ ПРИНЦИПОВ СПРАВЕДЛИВОСТИ И РАВЕНСТВА В ДОГОВОРНЫХ НАСЛЕДСТВЕННЫХ ОТНОШЕНИЯХ
}

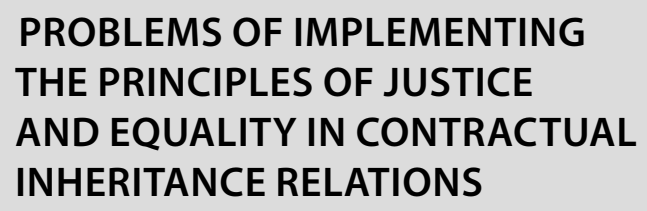

PROBLEMS OF IMPLEMENTING

THE PRINCIPLES OF JUSTICE

AND EQUALITY IN CONTRACTUAL INHERITANCE RELATIONS

\section{A. Spector}

Summary. The article considers the principles of justice and equality. The interrelation of these principles is justified, which is expressed in the fact that the principle of justice, implemented in the norms of law, ensures the equality of all before the law and the court, which actually embodies justice.

Keywords: equality, justice, civil law, inheritance relations, testator, inheritance contract.

\author{
Спектор Асия Ахметовна \\ Д.ю.н., nрофессор, Российский университет \\ транспорта \\ spector.a@mail.ru
}

Аннотация. В статье нашли свое рассмотрение принципы справедливости и равенства. Обоснована взаимосвязь указанных принципов, которая выражается в том, что принцип справедливости, реализованный в нормах права, обеспечивает равенство всех перед законом и судом, что собственно и воплощает справедливость.

Ключевые слова: равенство, справедливость, гражданское право, наследственные отношения, наследодатель, наследственный договор.

ющихся в обществе [5. С. 53]. Общеправовой принцип справедливости, его выражение и действие постоянно находятся в фокусе исследовательского внимания. Постановка вопроса о соотношении права (отдельных его отраслей и институтов) и справедливости является, как обосновано отмечает С.В. Корнакова, настолько изученным, что всякое новое к нему обращение рассматривается если не как повторение, то как попытка представить уже известное в какой-то новой форме [6. С. 64-70].

Применительно к тематике нашей статьи справедливость может пониматься так, как её в своё время видел Аристотель, т.е. как законность и равенство [4. С. 324]. В этом смысле справедливость была и остается сложной категорией, относясь в равной степени, как к морали, так и к правовому сознанию и праву как таковому. В этом смысле допустимо считать справедливость с одной стороны - морально этической ценностью, определяющей или воздействующей на право, а с другой - неотъемлемым свойством самого права, которое, в том числе направлено на достижение его цели [7. С. 45]. Важно, что обе категории не антагонистичны, а существуют во взаимодействии, так как объективно выраженная (социальная) справедливость влияет на право, становясь его особым, а возможно и доминирующим, целеполагающим качеством.

Применительно к наследственным отношениям, конституционно закрепленные принципы равенства и спра- 
ведливости призваны обеспечить определенность, непротиворечивость наследственно-правовой нормы, так как иное не обеспечит не только ее единообразное применение, но и достижение целей правового регулирования.

Не углубляясь далее в дискуссию о понятии и критериях «справедливости», отметим, что проблемным вопросом является вопрос ее закрепления. Поскольку она формально не закреплена ни в ст. 1 ГК РФ, то есть в основах гражданских правоотношений, ни в разделе 5 ГК РФ.

В то же время российский законодатель предусмотрел в ст. 6 ГК РФ при невозможности применения аналогии закона, осуществлять регулирование гражданско-правовых отношений, базируясь на аналогии права, а также ряде требований, среди которых присутствует и справедливость, которая также фигурирует в ряде правовых норм, как важный или обязательный критерий (статьи 622, 1100 ГК РФ [3] и др.).

Объективно «справедливость» лежит в основе всяких наследственных отношений, в том числе и в институте универсального наследственного правопреемства. В то же время, наследование как правовой институт призвано гарантировать в своей сфере баланс частных и публичных интересов при реализации конституционных прав на распоряжение своим имуществом на случай смерти, равно как и на принятие наследства. На справедливость указывает и обеспечительная ориентация закона, предоставляющая отдельным категориям субъектов наследственных отношений определенные правовые гарантии.

Классическое понимание справедливости как беспристрастности, объективности, соответствии нормам морали, нравственности, в конституционно-правовом смысле можно считать и «компромиссом интересов», что в полной мере применимо к договорным наследственным отношениям, так как не противоречит принципам договорного права.

Дифференциация «законности» и «справедливости» строится на понимании первой как строгом, обеспечиваемом государством порядке, а также представлении о второй как о нравственном идеале общественной жизни, имеющей определенную для каждого политико-правового режима и конкретно-исторического периода характеристику. То, что в одно время и в одной общественно-экономической формации считается справедливым, в другой таковым может не признаваться. В то же время, эти позиции как показывает исторический опыт, способны существенно трансформироваться.

Так, советская власть в первые месяцы своего существования считала наследование в любой форме клас- сово несправедливым, так как наследство могло быть лишь у эксплуататоров, однако, уже в 1920-е годы возродила институт наследования.

Следуя императиву ч. 3 ст. 17 Конституции РФ [1] реализация чьих-либо наследственных прав не должно нарушать права и свободы иных лиц. Таким образом, проявляется сформулированный Аристотелем правовой смысл справедливости, в этом же отражается назначение правосудия, призванного обеспечить восстановление нарушенных прав.

Таким образом, принцип справедливости, будучи по природе морально-нравственным, является фундаментом права, демонстрируя отношение общества и государства ко всем участникам правоотношений.

Принцип справедливости, реализованный в нормах права, обеспечивает равенство всех перед законом и судом, что, собственно, и воплощает справедливость.

Законодатель закладывал принцип справедливости в основу норм, которые закрепляют основания наследования: по завещанию, по договору и по закону. В первом случае наследник исходит из суждений субъективной справедливости, которая в данном случае выражена в проявлениях свободы воли наследодателя. Во втором случае, субъективный фактор объективизируется ввиду проявления согласованности воли наследодателя и наследника, закрепленной в договоре, условия и содержание которого стороны признают справедливыми, в отличие от завещания, которое наследник может счесть несправедливым. Что касается последнего случая - наследования по закону, то здесь проявляется социальная справедливость, когда закон закрепляет очередность наследников.

Полагаем, что именно вновь введенный институт наследования по договору позволяет проявиться и реализоваться принципу справедливости. Здесь присутствует не только и не просто возможность наследодателя распорядиться своим имуществом на случай смерти, но и согласование этого с наследником в наиболее демократичной, двусторонней, равной договорной форме, что соответствует также и принципу социальной справедливости.

Наследодатель, заключая договор, не просто диктует свою волю (как в случае с завещанием), а согласовывает её с наследником, предполагая заинтересованность в полезном применении собственности. Принцип свободы договора в данном случае следует соотносить и рассматривать в связке с принципом свободы завещания.

Принято считать, что основную социальную нагрузку в реализации принципа справедливости несет институт 
обязательной доли, защищая интересы тех членов семьи и/или близких наследодателя, кому в силу объективных причин необходима защита. В данном случае принцип справедливости определяет сущность института обязательной доли.

Государство, формально не вмешиваясь в наследственно-договорные отношения, тем не менее, ограничивает свободу воли завещателя, как и свой «нейтралитет» в пользу реализации публичного интереса - защиты нуждающихся лиц. Институт обязательной доли, распространенный и на наследственно-договорные отношения, отражает действие принципа справедливости в наследственном праве, будучи основным средством согласования прав наследодателя и его обязанностей по отношению к (материально) зависимым лицам [8. С. 338].

В свою очередь, институт наследственного договора соответствует принципу справедливости и в связи с тем, что способствует тому, что наследство переходит к тем, кому наследодатель доверяет, но не безусловно, как бы это было по завещанию, а при определенных условиях, которые он сам и определяет в договоре. Реализация принципа справедливости прослеживается и в регулировании в ч. 1 ст. 1140.1, с учетом ст. 327.1 ГК РФ последствий, предусмотренных наследственным договором. В частности, они могут ставиться в зависимость от на- ступивших ко дню открытия наследства обстоятельств, о которых при заключении наследственного договора не было ясности, включая и обстоятельства, зависящие от воли одной из сторон.

Законодатель учел и возможность возникновения новых обстоятельств, что также следует признать справедливым. Так, принимая во внимание ст. 327.1 ГК РФ последствия выполнения наследственного договора, могут попасть в зависимость от обстоятельств, которые наступили к моменту открытия наследства и о которых не было известно на момент подписания наследственного договора. В данном случае, законодатель, на наш взгляд, не вполне корректно сформулировал положение статьи. Так, об обстоятельствах указано следующее: «было неизвестно, наступят они или не наступят». Отсюда следует, что сами обстоятельства были известны, не ясно было лишь то, «наступят они или не наступят», т.е. фактическое их наступление и его время.

В завершение сделаем вывод о том, что в настоящее время нормы договорного наследственного права в основном соответствуют принципам справедливости и равенства, с одной стороны обеспечивая справедливое, с точки зрения наследодателя, распределение его имущества, а с другой - поддерживая стабильность наследственных отношений в целом.

\section{ЛИТЕРАТУРА}

1. Конституция Российской Федерации (принята всенародным голосованием 12.12.1993 с изменениями, одобренными в ходе общероссийского голосования 01.07.2020) // СПС «Консультант Плюс».

2. ражданский кодекс Российской Федерации (часть первая) от 30.11.1994 N51-Ф3 (ред. от 09.03.2021) // С3 РФ. 1994. N32. С. 3301.

3. Гражданский кодекс Российской Федерации (часть третья) от 26.11.2001 N146-Ф3 (ред. от 18.03.2019) // СЗ РФ. 2001. N49. Ст. 4552.

4. Аристотель. Большая этика // Соч.: в 4 т.: М., 1983. Т. 4. С. 324.

5. Иванова С.А. Принцип справедливости в гражданском праве России: дис. ... д-ра юрид. наук. М., 2006. С. 53.

6. Корнакова С.В. К вопросу о принципе справедливости// Сибирские уголовно-процессуальные и криминалистические чтения. 2014. № 2 (6). С. 64-70.

7. Курбатов А.Я. Справедливость в российском праве: подмена понятий, субъективизм и неопределенность // Вопросы правоведения. 2012 . № 3. С. 44-64. C. 45.

8. Омарова У.А. Принцип социальной справедливости в праве на обязательную долю в наследстве// Проблемы современной цивилистики: Сб. статей. отв. ред. Е.А. Суханов М., 2013. С. 338.

9. Трубникова К.Д., Мокрова А.А. К вопросу об источниках и принципах наследственного права// Е-Scio. 2020.№ 1 (40). С. 356-364. 